\title{
Who determines food prices? ---Based on the Simulation analysis of China Economy-wide Multi-market Model
}

\author{
XU Shi-wei ${ }^{1,2}$, Zhang Yu-mei ${ }^{1,2}$, LI Zhe-min ${ }^{1,2}$, KONG Fan-tao ${ }^{1,2}$,Wang yu ${ }^{1}$, Cui Li-guo ${ }^{1}$ \\ ${ }^{1}$ Agricultural Information Institute of Chinese Academy of Agricultural Sciences, Beijing 100081, \\ China \\ ${ }^{2}$ Key Laboratory of Agri-information Service Technology, Ministry of Agriculture, Beijing \\ 100081, China
}

\begin{abstract}
:
Food prices kept rising up and had affected residents' life quality during recent years. Food prices trends and the determinants behind attract wide attentions. China Economy-wide Multi-market Model(CEMM) is constructed to simulate the price effects of supply and demand in this paper. Three scenarios are designed to access the price effects of supply, demand and their combine effects, respectively. The results shows that the production costs rising and constrained supply are the main important factors which lead to food prices rising. The boosting demand for maize as industrial use and livestock products also put a great pressure on food price rising. Ensuring the supply of main grains and meats is one of important tasks for the government to stabilize the price. So, the fourth scenario is designed to evaluate the price effects of the increase in production. The model simulation results evident that the improvement of productivity is an effective measure to slow rising food price.
\end{abstract}

Keywords: food price, China Economy-wide Multi-market Model (CEMM), simulation

\section{Introduction}

Since 2001, especially since 2007, food prices kept rising up in China and around the world, food seems to enter the era of high price. China's food price index has risen 85 percents, and its annual average growth rate was 6.32 percent during 2001 to 2010 . The price indexes of grains and eggs were nearly doubled; the prices of meats, vegetables and fruits fluctuate widely, while their prices trends kept rising during the year of 2001-2011. The rising food prices lead to higher living cost. The Engel coefficient (the share of food expenditure in total living expenditure) unusually turned to rise than fall. The Engel coefficient of urban residents rose from $35.8 \%$ in 2006 to $36.3 \%$ in 2007 and $37.9 \%$ in 2008. The Engel coefficient of rural residents rose from $43 \%$ in 2006 to $43.1 \%$ in 2007 and 2008. In another word, the rising food prices have affected the residents' life quality.

Will the food prices continue to rise in the future? Who determines the food prices? Food prices are affected by many factors at home and abroad, and the future prices are unpredicted. However, supply and demand are still the basic determinants. So, it is important to analyze the price factors from supply and demand side, and quantitatively evaluate their effects. These will not only help us to better understand the future market situation, but also are useful for the government to play the role of macro-readjustment in the agricultural market.

Agricultural Information Institute of Chinese Academy of Agricultural Sciences introduced a partial equilibrium model named Economy-wide Multi-market Model (EMM) from the International Food Policy Research Institute (IFPRI) (Diao, et al, 2007a, 2007b, 2008), and developed China EMM model (CEMM). Compared with other partial equilibrium models, a very significant feature of CEMM model is that CEMM not only includes agricultural sectors, but also includes non-agricultural economy, such as industry and services, and puts the agricultural market analysis in a macroeconomic background. CEMM model can be used to simulate the shocks of various external factors to agricultural markets, but also can be used to project and analyze the trends of agricultural market.

This paper analyzes factors of supply and demand which influence the price of mainly food (grains and meats) in the near future 
firstly, and then applies CEMM model to simulate the price effects of these supply and demand factors, and explores the role of the increase in the food supply to stabilize food prices.

\section{The influences of supply and demand on food prices}

The food prices rising have attracted extensive attention since 2007. The reasons of food prices rising were discussed hotly and the main reasons are as follows: first, excessive money supply (Hu et al. 2009); second, the rising production cost of agricultural product (Cheng et al. 2008; Li 2008); third, the decrease in agricultural products supply due to the natural disasters and the cyclical fluctuation and other factors related with agricultural production; fourth, the spurring demand, for example, mass production and use of biofuel drive the demand increase for corn and other agricultural products (Qiu et al. 2009); fifth, the price transmission of the international agricultural market to the domestic agricultural market(Wang and Xie,2012); sixth, speculative factors. This paper analyze the price effects on food from the supply and demand side $t$.

\subsection{The changes in food demand}

Food demand is changing due to many factors, such as population growth, economy development and income increase, diversity of agricultural products use and others.

(a) Population growth. China's total population reached 1.35 billion in 2011 . The natural population growth rate was around $0.5 \%$, and about 700 million populations increased annually during recent years (NBS, 2012). The population growth drives new food demand.

(b) Economy development and income increase. China's economy maintained rapid growth in recent years. The real growth of GDP was $9.2 \%$ in 2011. Economic growth slightly slow down, but GDP still kept a rapid growth with $7.7 \%$ in the first three quarters of 2012 (NBS, 2012). Accompanied with rapid economic development, households' income grew fast. The per capita net income of rural households closed to 7000 yuan with a nominal growth rate of $17.9 \%$ and real growth of $11.04 \%$; the per capita disposable income of urban households were over 20,000 yuan, reached to 21,810 yuan with a nominal growth rate of $14.1 \%$ and a real growth rate of $8.4 \%$ in 2011. According to the forecast from the Chinese Academy of Social Sciences, per capita net income of rural households will be over 8000 yuan with the real growth rate of about $10 \%$ in 2012. Therefore, the rapid income growth stimulates the demand for food, especially the demand for meats. And the increase of meats demand requires more grains as feed.

(c) Diversity of agricultural products use. According to the statistics from administrations of grains, industrial grains use was about 93 million tons in 2010, including 9.1 and 10.7 million tons of rice and wheat, 13.4 million tons of maize and 50.1 million tons of soybeans. With the prices rising of starch and alcohol, the demand for deep processing of maize becomes the dominant force to promote corn consumption, and the quantity of Industrial use of corn is more than one-third of the total maize consumption.

(d) Other factors. Other factors include some policy factors and unexpected factors. For instance, the improvement of new rural cooperative medical system, the insurance benefit and the ratio of reimbursement, basically, $75 \%$ of all kinds of hospital costs would be reimbursed in 2012. So, the new policy mitigates farmers' considerable worries and farmers can spend more money on consumption.

\subsection{The Changes in the Supply}

The supply is mainly constrained by the natural resources and the rising production cost, but fortunately, Chinese government took many measures to promote food, especially grains production.

(a) Rising production costs

In recent years, agricultural production costs, such as labor costs, production material costs, machinery operating costs, and the land rent etc. ,kept rising. The average cost of production of major agricultural products such as grains, oilseeds, vegetables and pigs rose by about $60 \%$ during 2006 to 2011 , and the average annual growth rates were about $10 \%$. For grains production, the labor costs rose particularly fast with about $25 \%$ increase in 2011 than that of 2010, land costs and the material costs increased by $12 \%$ and $14 \%$, respectively.

(b)Continuous Policy Promotion 
Government policy supports ensures the stable growth of grains production, and grains production marked the nineth consecutive year of growth in 2012. Government continued to increase agricultural subsidies, and also raised the minimum grains purchase price gradually. Agricultural subsidies exceeded 140 billion yuan, and the minimum procurement price of wheat increased to 2.04 yuan per kilogram in 2011. For the important livestock, there are also a few subsidy policies. For example, the subsidy to breeding sows is to boost pork production.

\section{CEMM model and data sources}

\subsection{CEMM model}

EMM is a partial equilibrium model developed by XinShen Diao, who is senior research fellow of the International Food Policy Research Institute (IFPRI). According to the characteristics of China's agricultural market, an adaptive development is done for China's EMM model in this paper, named CEMM. The EMM model is based on neoclassical microeconomic theory. The framework of this CEMM is shown as in Figure 1.. The basic principles of supply and demand determine the price. Supply is composed by domestic production and import, demand includes domestic consumption and export. In the crop subsectors, the supply functions have two components: yield and land area. The demand is disaggregated into five demand types according its uses, such as the demands of food, feed, processing, seed, waste and other use. Different demand type is determined by different factor.

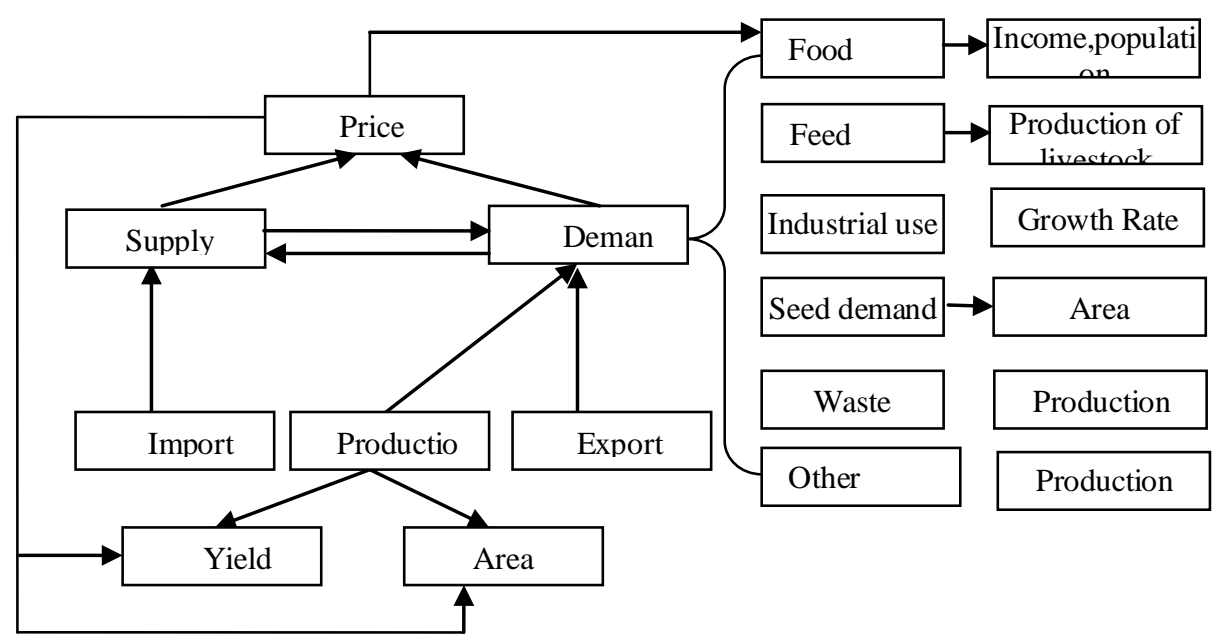

Fig.1. The framework of CEMM model

The CEMM model includes 37 agricultural sectors, such as grains, meats and other agricultural commodities, as well as two nonagricultural sectors. All sectors are listed in Table1. The sectoral linkages are shown as Figure2. Different sectors are linked through production, income, consumption and price. Producer prices determined the production of all sectors. The total of production value or output of all sectors composes the Gross Domestic Product (GDP), which decides the households' income. The total income is allocated to rural and urban household, which determine their purchasing power and demand.

Table1. Sectors list in China Economy-wide Multimarket Model

\begin{tabular}{|c|c|c|c|}
\hline Sector name & Sector name & Sector name & Sector name \\
\hline rice & sesameseed & cattle & Sea fish \\
\hline wheat & other oil crop & chicken & Fresh water fish \\
\hline maize & bastfibre & goat & Cotton seed oil \\
\hline other creal & sugarcane & Pigs & Groundnut oil \\
\hline soybean & sugarbeet & Cattle meat & Soybean oil \\
\hline other beans & tea & Chick meat & Sesame oil \\
\hline
\end{tabular}




\begin{tabular}{|c|c|c|c|}
\hline tuber crop & Tobacco & goat meat & Rapeseed oil \\
\hline cotton & fruits & pig meat & Other plant oil \\
\hline groundnuts & vegetables & Milk & industry \\
\hline rapeseeds & & Egg & construction and service \\
\hline
\end{tabular}

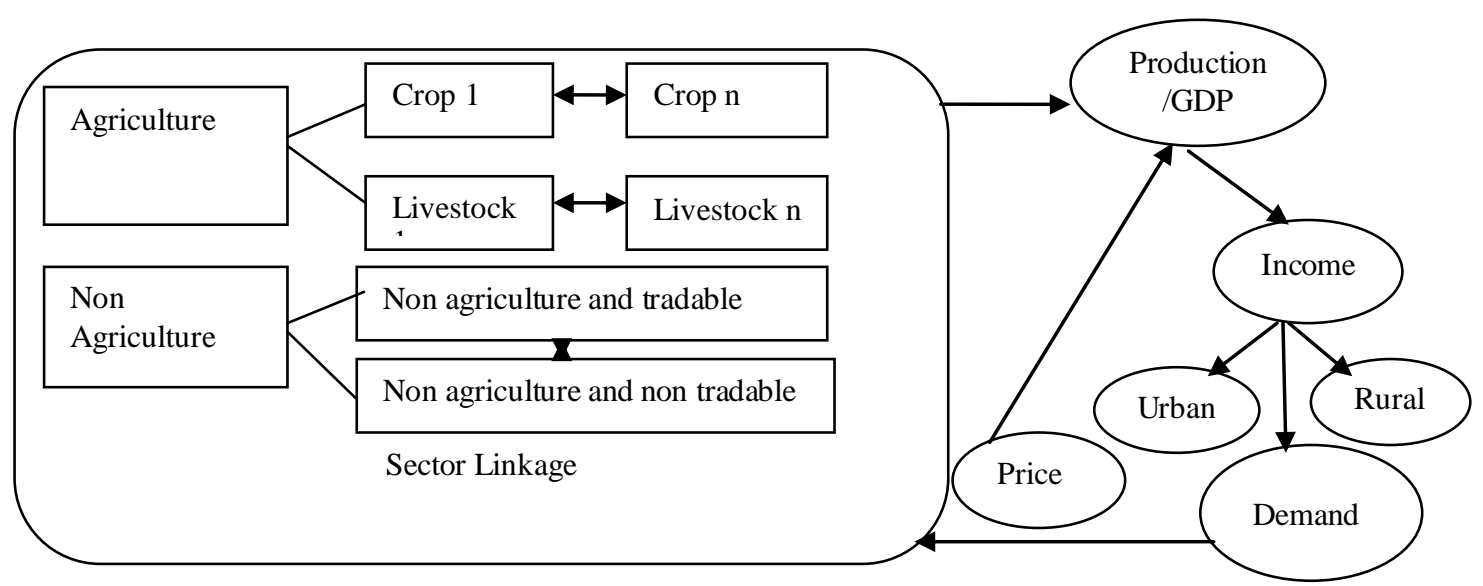

Figure 2. The Sectoral Linkages of CEMM model

The base year of the model is 2010. CEMM is a system model including a set of equations, such as supply equations, demand equations, import and export equations and equilibrium equations, GDP, income and price equations etc. And mutual linkages among sectors are built through these equations. And all the equations are listed in the Appendix. The supply function is used to capture each representative producer's response to market under producer profit-maximization. The supply is determined by the producer prices of all commodities (including the prices for two aggregate nonagricultural commodities). The production of meats are determined by the production of cattle, pig and sheep/goat, poultry. Eggs and milk are also the byproducts of poultry, cattle, and sheep. Each type of demand has different equation. Considering the big difference consumption between rural and urban households in China, the food demand function for rural and urban households are separated in the model. Food demand mainly depends on income, the price of the product itself, prices of related commodities, population size and urbanization. Processing demand is mainly determined by the economy development and the productions of its industrial products. Areal is the main factor to decide the seed usage. The data of wastages are assumed proportionally with production, while the waste rates are different among different commodities. Other use is the residue, include the storages. There is perfect substitution between domestically and internationally produced commodities. However, marginal transaction cost (transportation and other market costs) distinguishes trade in the domestic market from imports and exports. Imports primarily relate to international imports prices, domestic consumer prices and transactions costs, exports mainly depend on the international prices of exports, the domestic producer price and transactions costs. Distinguished from most partial equilibrium, the per capita income is an endogenous variable in the CEMM model. Because of such setup, the model has a general equilibrium nature which allows production and consumption decisions are linked. Producer prices are adjusted to represent value add, the aggregation of agricultural production at the value add prices equals agricultural GDP (AgGDP). For the two nonagricultural sectors, the sector level GDP is used to represent production output with unit price. And AgGDP and nonagricultural GDP are comprised the GDP.

\subsection{Data sources}

The data of CEMM model include production, yield, area, food consumption, processing consumption, feed consumption, seed consumption, losses and other consumption, import, export, price, GDP, industrial GDP, population and other indicators. Most of the data are from the various Statistical Yearbook of China, such as "China Statistical Yearbook", "China Agricultural statistics compiled by the sixty years", "China Yearbook of Rural Household Survey", "Compilation of the National Agricultural Costs and Returns", "China Yearbook of Agricultural Price", as well as the official website of government departments, and also some data are from Food and Agriculture Organization of the United Nations(FAO). Some data which cannot get officially are estimated by authors. For instance, feed grains demands are calculated from livestock production, and industrial grains demands are calculated from their 
proceeding products, and seed demand is calculated according the crop sowing area. The most important data work is to check the data consistently and make sure the balances of supply and demand for each commodity.

\subsection{Parameter Estimation}

The parameters used in CEMM mainly include income elasticity, price elasticity of demand and price elasticity of supply. The parameters are mainly from domestic and international research results, as well as empirical analysis based on historical data. Some parameters are calculated according to the equations of the CEMM model. The income elasticities of all kinds of foods demand for rural households are estimated in this paper using 6199 sample of 2009 China Rural Household Survey, and following the method of Inverse function of the Ratio Semi-log.

\section{CEMM model simulation and result}

\subsection{Simulation design}

Table 2. Non-base Scenarios

\begin{tabular}{|c|c|c|}
\hline Scenario & Objective & Content/Assumption \\
\hline S1 & $\begin{array}{l}\text { To analyze the impacts of supply } \\
\text { factors }\end{array}$ & $\begin{array}{l}\text { The rising of production costs result in the decrease of } \\
\text { supply elasticity }\end{array}$ \\
\hline S2 & $\begin{array}{l}\text { To analyze the impacts of demand } \\
\text { factors }\end{array}$ & $\begin{array}{l}\text { Economic growth rate accelerates } 20 \% \text {, and the increase in } \\
\text { industrial demand }\end{array}$ \\
\hline S3 & $\begin{array}{l}\text { To analyze the combined effects of } \\
\text { supply and demand factors }\end{array}$ & Combined with the above two factors \\
\hline S4 & $\begin{array}{c}\text { To analyze of the effects of policy } \\
\text { measures }\end{array}$ & Taking measures to increase the supply \\
\hline
\end{tabular}

\subsection{Simulation results}

\section{(a)Base scenario}

The base year is 2010. In order to confirm the effectiveness of the benchmark, the results of 2011 are also listed separately. It is clear to see, although the model only take into account the supply and demand, the model simulation results of production, consumption and price are close to the reality of the situation, which are listed in the first and second column in Table 3 to Table 5. It shows CEMM model can basically reflect the real economy. According to the historical data of population, the nonagricultural GDP and other new situations, the market situations are simulated in 20122013. For example, the price of maize is higher than wheat price in 2011, so, large amount wheat was used as feed instead of maize, and the quantity was estimated about 14 to 18 million tons. As a result, the feed structures have been changed, namely, the conversion ratios of feed grains and meat have been changed too.

So, if according to the normal historical trends of supply and demand, during 2011-2013, the average annual growth rate of gain productions is about $1 \%$, and (a) Assumption

Considering high self-sufficiency rate of grains and meats in China, and very few import and export, thus, market price is primarily determined by domestic supply and demand. Here, we assume there are no trade for grains and meats, and their price is primarily determined by domestic supply and demand factors. Considering this assumption, only the short-term situation is simulated.

(b) Scenarios

The base scenario is used as benchmark for nonbase scenarios to measure the shock effects of the nonbase scenarios. Non-base scenarios simulate the impacts of shocks or the effects of policies. In this paper, we will answer the following two questions: first, how big effects of the changes of supply and demand would have to the future prices of grains and meats? Second, what kind of measures should be taken to ensure the supply and meet consumer demand needs? And if the supply increases, what kind of impacts might be on the prices of grains and meats?Thus, the four non-base scenarios are designed as showed in Table 2. the growth rate of maize will be larger with about 5.04\%; poultry production will be increased faster than other meats with the average annual growth rate of $2.61 \%$, pork production will be increased with the average annual growth rate of $0.97 \%$. Beef and mutton production will be changed a little. Because meats mainly are used as food, so, the growth rates of meats demand and supply are same, here, the description of meats demand is omitted.

Because of wheat used as feed instead of maize, CEMM is adjusted through new feed conversion ratio to reflect the new situation and estimates the feed demand for wheat and maize. During the base year of 2010, about 15.44 million ton wheat was used as feed in the model. TBecause wheat price will rise up with the increase in feed demand, wheat price would not be always lower than maize price, at the same time, constrained by technique, the substitution space will become smaller. The feed conversion ratios would not change during 2011-2013.

The grain processing increases rapidly, especially maize processing would increase with the fastest average annual growth rate of $13.75 \%$. As food consumption, grains demand would increase stably 
because it mainly depends on the population growth rate. The average annual growth rate of rice demand would be $0.99 \%$.

The prices of main products of grains and meats would keep rising during 2012-2013. The annual growth rate of maize price will be slightly faster than these of wheat and rice with more than $11 \%$, while the annual growth rate of poultry price will be more modest than the other meat prices with about $6 \%$, and pork price will be rise by nearly $10 \%$ annually.

(b) Non-base scenario

The objective of Scenario 1 is to analyze the impacts of the increase in production costs on price. Compared with the base scenario, both the productions and consumptions of grains and meats would be reduced due to the higher production cost, while their prices rise faster than the base. If the average annual growth rates of rice and wheat production are both only about $0.5 \%$, the prices of rice and wheat rise obviously, the average annual growth rates will be $12.63 \%$ and $15.18 \%$, respectively. Due to the prices rising sharply, the growth rates of rice and wheat as food consumption slow down to $0.2 \%$. It is similar to the industrial use of rice and wheat. The rice used as feed even decreased. Similar to rice and wheat, the growth rate of maize production will be down to $3.14 \%$, while the price will rise $17.42 \%$. Affected by the excessive price hike, the growth rates of maize for industrial use and maize for food slow down, and the growth rate of maize for feed will be slightly negative. Due to the higher feed price, the meats production would be decreased slightly in Scenario 1, except poultry prices will rise $6.59 \%$, while the prices of other meats prices will rise faster with about $12 \%$.

Scenario 2 is designed to analyze the effects on prices of the increase demand for maize deep processing industry driven by the rapid economy development. All kinds of demand for rice and wheat are slightly higher than the base. The annual growth rate of maize demand is up to $17.62 \%$, which is much higher than that of in baseline with $11.03 \%$. As a result, the prices of rice and wheat increase less than that of maize, maize price rises faster with the annual growth rate of $15.09 \%$. The maize production increases more than the base to respond to the much higher maize price with the annual growth rate of $6.04 \%$, while rice and wheat productions would be slightly lower than the base. Affected by the rising prices of grains, especially maize, the meat production cost would be increased, which will restrict the supply. Except for the growth rate of poultry production will be slightly higher than that of the base, the growth of production of other meats will be slightly lower than the base, and lead to the rise in meats prices.

Scenario 3 is used to access the impacts of the two combined factors. Under the combined effects of two factors in Scenario 3, the growth rates of grains production will be a little higher, while the growth rate of meats production will decline slightly. On the other hand, the demand for both of grains and meats will be still strong. Thus, the prices of grains and meats will rise more than $13 \%$, and the price of maize will rise especially faster with the growth rate of more than $20 \%$. It shows the food prices would rise excessively rapidly under the double effects of the supply and demand factors.

From the analysis of Scenario 1 to Scenario 3, it is easy to find that the main reasons behind the rising food prices are supply constrained. Moreover, the macrocontrol policies emphasize the importance of ensuring supply. Therefore, Scenario 4 simulates the market regulative effects of the measures taken by government to increase the productions. The simulation results of Scenario 4 show that the production of most of grains and meats will be slightly higher than the base, and their prices growth rates will slow down significantly, especially the prices of rice and wheat will be lower than the base. However, due to the rapid growth of demand for maize, the growth rate of maize price will keep at about $14 \%$. The high maize price pulls the prices of livestock, but the growth rate of meats prices slowdown, which not only are significantly slower than Scenario 3, but also slower than the base. Because the prices rise slower, the various demands are increased faster.

Table 3. Annual Average Growth Rates of the Productions of Grains and Meats during 2011-2013 (\%)

\begin{tabular}{cccccccccc}
\hline \multirow{2}{*}{ Commodity } & $\begin{array}{c}2010 \\
\text { ( million tons }\end{array}$ & $\begin{array}{c}2011 \text { (actual } \\
\text { growth rate) }\end{array}$ & $\begin{array}{c}\text { 2011 (Model } \\
\text { growth rate) }\end{array}$ & Base & S1 & S2 & S3 & S4 \\
\hline Rice & 1958 & 2.56 & 2.96 & 1.56 & 0.44 & 1.42 & 0.52 & 1.66 \\
Wheat & 1161 & 2.37 & 2.34 & 1.43 & 0.62 & 1.08 & 0.37 & 1.09 \\
Corn & 1787 & 8.18 & 8.70 & 5.04 & 3.14 & 6.40 & 4.66 & 5.95 \\
Beef & 65 & & -0.92 & 0.11 & -0.21 & 0.03 & -0.34 & 0.60 \\
Poultry & 167 & & 3.41 & 2.61 & -0.51 & 2.91 & -0.18 & 3.75 \\
Mutton & 40 & & -1.59 & -0.11 & -0.43 & -0.20 & -0.56 & 0.60 \\
Pork & 507 & 0.4 & 0.37 & 0.97 & -0.23 & 0.79 & 0.05 & 1.70 \\
\hline
\end{tabular}

Source: model simulation results 
Table 4. Annual Average Growth Rates of the Demands of Grains during 2011-2013 (\%)

\begin{tabular}{|c|c|c|c|c|c|c|c|}
\hline Commodity & 2010(million tons) & 2011 Model & Base & S1 & $\mathrm{S} 2$ & S 3 & S4 \\
\hline \multicolumn{8}{|c|}{ Rations demand } \\
\hline Rice & 1088 & 1.53 & 0.99 & 0.29 & 1.09 & 0.35 & 1.53 \\
\hline Wheat & 810 & 0.87 & 0.65 & 0.27 & 0.71 & 0.33 & 1.05 \\
\hline Corn & 154 & 0.73 & 0.46 & 0.18 & 0.35 & 0.07 & 0.28 \\
\hline \multicolumn{8}{|c|}{ Feed demand } \\
\hline Rice & 102 & 0.67 & 1.12 & -0.37 & 1.13 & -0.21 & 1.97 \\
\hline Wheat & 135 & 14.38 & 5.58 & 2.01 & 1.41 & -0.21 & 2.15 \\
\hline Corn & 1070 & 0.63 & 1.11 & -0.57 & 1.11 & -0.21 & 1.97 \\
\hline \multicolumn{8}{|c|}{ Processing demand } \\
\hline Rice & 91 & 12.97 & 5.51 & 2.99 & 5.78 & 3.28 & 3.45 \\
\hline Wheat & 1,07 & 2.70 & 3.57 & 1.10 & 3.84 & 1.38 & 1.55 \\
\hline Corn & 503 & 28.38 & 13.75 & 11.03 & 17.63 & 14.85 & 15.03 \\
\hline
\end{tabular}

Source: model simulation results

Table 5. Annual Average Growth Rates of Producer Prices of Grains and Meats during 2011-2013 (\%)

\begin{tabular}{ccccccccc}
\hline Commodity & 2010(million tons) & $\begin{array}{c}\text { 2011 (actual } \\
\text { growth rate) }\end{array}$ & $\begin{array}{c}\text { 2011 (Model } \\
\text { growth rate) }\end{array}$ & Base & S1 & S2 & S3 & S4 \\
\hline Rice & 182.6 & 4.43 & 4.79 & 12.63 & 4.87 & 13.44 & -1.77 \\
Wheat & 160.4 & 8.13 & 6.27 & 15.18 & 5.81 & 15.10 & -4.61 \\
Corn & 158.9 & 11.07 & 11.12 & 17.42 & 15.09 & 22.40 & 14.64 \\
Beef & 2857.7 & 15.85 & 10.92 & 11.24 & 12.38 & 12.96 & 11.47 \\
Poultry & 1188.9 & 7.60 & 5.96 & 12.25 & 6.59 & 13.01 & 4.72 \\
Mutton & 3123.9 & 18.91 & 11.72 & 12.10 & 13.16 & 13.87 & 10.95 \\
Pork & 1329.4 & 15.43 & 9.65 & 11.99 & 11.27 & 12.90 & 8.44 \\
\hline
\end{tabular}

Source: model simulation results

\section{Conclusion and Discussion}

This paper analyzes the supply and demand factors influencing food prices, and applies CEMM model to simulate the changes of food prices. The results reveal that the food prices rising are affected by the combined factors of supply and demand. Rising production costs and slow growth of supply are the most important factors which lead to food prices rising. From the demand side, firstly, the rapid growth of the industrial use demand for maize, not only lead to maize prices rising, but also generates important effects to the prices of other grains and meats; secondly, the rapid economic development and the improvement of households' living standards stimulate the demand for more livestock products. The constrained supply and boosting demand put a great pressure on food price. Ensuring the supply of agricultural products, especially the supply of main grains and meats is one of important government's tasks, and it is also one of most effective measures to stabilize the prices of agricultural products.

\section{References}

[1] Diao, X., Nin Pratt, A., "Growth options and poverty reduction in Ethiopia - An economy-wide model analysis", Food Policy, vol. 32, no. 2, pp. 205-228, 2007.

[2] Diao, X., Shenggen Fan, Sam Kanyarukiga and Bingxin Yu, "Agricultural Growth and Investment Options for Poverty Reduction in Rwanda", IFPRI Discussion Paper. International Food Policy Research Institute (IFPRI), Washington, DC, 2007.

[3] Diao, X., Fan, S., Headey, D., Johnson, M., NinPratt, A., Yu, B., "Accelerating Africa's food production in response to rising food prices Impacts and requisite actions", IFPRI Discussion Paper. International Food Policy Research Institute (IFPRI), Washington, DC, 2008.

[4] Hu,B., Xu, F.,Dong, X, "The analysis of price volatility influencing factors of International Agricultural product-based on time series Econometric model", Chinese Rural Economy, no. 7, pp.86-95, 2009(in Chinese).

[5] Cheng,G., Hu, B., Xu,.X., "An Analysis of the Impact of the New Round of Rise in the Prices of Agricultural", Produce Management World, no. 1, pp.56-62, 2008(in Chinese).

[6] Li,G, "Prices rising of global agricultural product and its effects to the prices of Chinese agricultural product", Agricultural Outlook, no. 7, pp. 32-35, 2008(in Chinese). 
[7] Qiu,H. Yang, J., Huang, J, "Bio-fuel Ethanol development and its effects to grains price", Issues in Agricultural Economy, no. 1, pp. 80-85, 2009(in Chinese).

[8] Wang, X., Xie, S., "How Do Prices of Foreign Agricultural Products Affect Prices of Chinese Agricultural Products", Economic Research Journal, no.3, pp. 141-153, 2012 (in Chinese).

[9] NBS (National Bureau of Statistics of China). China Statistical Yearbook of 2012, Beijing: China Statistics Press,2012.

[10] NBS (National Bureau of Statistics of China). The GDP of the first three quarters of 2012, http://www.stats.gov.cn/tjfx/jdfx/t20121023_402844 638.htm, accessed on Jan 10 (in Chinese), 2012.

Appendix

\section{CEMM Model equations}

\section{Supply function for Crop supply function}

\section{Crop Yield Function}

$$
Y_{i, t}=Y A_{i, t} P_{i, t}^{\alpha_{i}}
$$

Where $Y_{i, t}$ is the yield for crop $i$ at time period $t$, and $P_{, i}$, ${ }_{t}$ is the producer price for $i$. $Y A_{i, t}$ is the productivity shift parameter.

Trends in the Crop Yield Function $\mathrm{YA}_{i, t+1}=\mathrm{YA}_{\mathrm{i}, \mathrm{t}}\left(1+g_{Y_{i}, t}\right)$

Where $g_{Y_{i, t}}$ is the annual productivity growth rate.

\section{Crop Area Function}

$A_{i, t}=\mathrm{AA}_{\mathrm{i}, \mathrm{t}} \prod_{j} P_{j, t}^{\beta_{j}}$

Where $A_{i, t}$ is the area for crop $\mathrm{i}, \mathrm{P}_{1}, \mathrm{P}_{2}, \ldots \mathrm{P}_{\mathrm{J}}$, are the producer prices for all crop commodities,

$\mathrm{AA}_{i, t}$ is the shift parameter.

Trends in the Crop Area Function

$$
\mathrm{AA}_{i, t+1}=\mathrm{AA}_{\mathrm{i}, \mathrm{t}}\left(1+g_{A_{i, t}}\right) \text {, }
$$

where $g_{A_{i, t}}$ is the annual area expansion rate for crop $i$.

\section{Crop Production Function}

$S_{i, t}^{c r o p}=Y_{i, t} \cdot A_{i, t}$

Where $s_{i, t}^{c r o p}$ is the supply for crop i.

\section{Supply Function for Noncrop Sectors (livestock and nonagriculture)}

$$
S_{i, t}^{L V}=\mathrm{SA}_{\mathrm{i}, \mathrm{t}}^{\mathrm{LV}} \prod_{j} P_{j, t}^{\beta_{j}^{L V}}
$$

Where $s_{i, t}^{L V}$ is supply for livestock i, $S A_{i, t}^{L V}$ is productivity shift parameter, $P_{1, t}^{L V}, P_{2, t}^{L V} \ldots . . P_{J, t}^{L V}$ is the producer prices for all livestock, for $\beta$ is supply price elasticity.

Trends in the Livestock and Nonagricultural Supply Function

$$
\mathrm{SA}_{\mathrm{i}, \mathrm{t}+1}^{\mathrm{LV}}=\mathrm{SA}_{\mathrm{i}, \mathrm{t}}^{\mathrm{LV}}\left(1+g_{S_{i, t}}\right)
$$

Where $g_{S_{i, t}}$ is the annual growth rate of livestock and nonagricultural productivity.

Meat Supply Functions

$S^{\text {meat }}{ }_{i, t}=\sum_{\text {lvlivel }} \mathrm{IOXX} 1_{\text {lvliveli }} * D_{\text {lvlivel }, t}^{P}$

$s_{\text {lvlivel, } t}^{\text {meat }}$ is the supply of meat. IOXX $1_{\text {lvlivel }, i}$ is the

conversion coefficient between livestock and meat.

$D^{P}$ lvlivel, $t$ is the procees demand of livestock.

Egg/milk supply function

$S_{i, t}^{\text {eggmilk }}=\sum_{\text {lvlive } 2} \mathrm{IOXX} 2_{\text {lvlivezi, }} * S_{\text {lvlive }, t}$

$s_{i, t}^{\text {eggmilk }}$ is the supply of egg/milk, IOXX $2_{\text {lvlivel }, i}$ is the conversion coefficient between livestock and milk/egg, $S_{\text {lvlive2,t }}$ is the supply of livestock.

Processed oil supply function

$S_{i, t}^{\text {oil }}=\sum_{\text {oilseed }} \mathrm{IOOIL}_{\text {oilseedi }} * D_{\text {oilseed }, t}^{p}$

$s_{i, t}^{o i l}$ is the supply of oil, IOOIL $L_{\text {oilseed, } i}$ is the conversion coefficient between oil and oilseeds,

$D^{P}{ }_{\text {oilseed, } t}$ is the oilseed process demand.

Demand function

Rural and urban household Per Capita Demand Function

$$
D p c_{i, H, t}^{F}=A_{i, H, t}^{F} * \prod_{j} P D_{j, t}^{e_{i, j, H}^{f}} *\left(I N C_{H, t} / \operatorname{pop}_{H, t}\right)^{e_{i, H}^{I}}
$$

Where $D p c^{F}{ }_{i, H, t}$ is per capita demand for commodity $i$, INC is income, pop is population. PD is consumer price, $e_{R, i, j, H}$ is price elasticity between demand for commodity $i$ and price for commodity $j$, and $e_{R, i, H}^{I}$ is income elasticity.

\section{Rural and urban household total food Demand} Function

$$
D_{\mathrm{i}, H, t}^{F}=D p c_{i, H, t}^{F} * \operatorname{pop}_{\mathrm{i}, H, t}
$$

Rural household total food demand is equal per capita demand product its population.

Total food demand function

$$
D_{i, t}^{F}=\sum_{H} D_{i, H, t}^{F}
$$

Total food demand equal to the sum of all households.

Per capita food demand function 


$$
D p c_{i, t}^{F}=D_{i, t}^{F} / \sum_{H} \text { pop }_{H, t}
$$

Per capita food demand equal to total food demand divide to total population.

Feed demand function

$D_{i, t}^{L}=\sum_{j} I O X L_{i, j} * S_{j, t}^{L V}$

$D^{L}{ }_{i, t}$ is feed demand , $I O X L_{i, t}$ the input and output

coefficient of feed and meat , $s_{j, t}^{L V}$ is the product of

livestock products.

Seed demand function

$D_{i, t}^{S}=I O X S_{i} * A_{i, t}$

$D^{S}{ }_{i, t}$ is seed demand, $I O X S_{i, t}$ is seed demand per unit

of crop area, $A_{i, t}$ is the crop area。

Processing demand function

$D_{i, t}^{P}=A P_{i, t} * P X_{\text {nagntrude }, t}^{0 . \alpha^{*}\left(\alpha_{i}+\beta_{i}\right)} * G D P^{0.2} *\left(\alpha_{i}+\beta_{i}\right)$

$D^{P}{ }_{i, t}$ is processing demand, $\mathrm{PX}$ is the producer price

Waste demand function

$D_{i, t}^{W}=\mathrm{IOXW}_{i} * S_{i, t}$

$D^{W}{ }_{i, t}$ is waste demand, IOXW is the ratio of waste

demand and total production, $S_{i, t}$ is the production

Other demand function

$D_{t}^{O}=\mathrm{IOXO}_{i} * S_{i, t}$

$D^{O}{ }_{i, t}$ is other demand, IOXO is the ratio of other

demand and total production, $S_{i, t}$ is the production

Total demand function

$D_{i, t}^{T}=D_{i, t}^{F}+D_{i, t}^{L}+D_{i, t}^{S}+D_{i, t}^{P}+D_{i, t}^{O}+D_{i, t}^{W}$

The sum of food, feed, seed, processed, waste and other demand.

Trade function

Export demand function

$P X_{i, t} /\left(1-m \arg W_{i, t}\right)>P W E_{i, t}$

$P X_{i, t}$ is producer price , $m \arg W_{i, t}$ is marginal cost ,

$P W E_{i, t}$ is international price.

Import demand function

$P W M_{i, t} *\left(1+m \arg W_{i, t}\right)>P D_{i, t}$

$P W M_{i, t}$ is international import price, $m \arg W_{i, t}$ is

marginal trade cost, $P D_{i, t}$ is consumer price.

\section{Balance function}

$S_{i, t}+M_{i, t}-E_{i, t}=D_{i, t}$

Where $S_{i, t}$ is the production, $M_{i, t}$ is the import, $E_{i, t}$ is

the export, $D_{i, t}$ is the demand.

GDP and Income

GDP Function
$G D P_{t}=\sum_{j} P X_{i, t} * S_{i, t}$

Where GDP is gross domestic output, $P X_{i, t}$ is producer price, $S_{i, t}$ is the production.

Income Function

$I N C_{i, t}=\sum_{i} \operatorname{incsh}_{i, H, t} * P X_{i, t} * S_{i, t}$

$I N C_{i, t}$ is income, incsh $_{i, H, t}$ is rural and urban

household income share, $P X_{i, t}$ is producer price, $S_{i, t}$ is the production.

Producer and Consumer Price Function

$P X_{i}^{*}\left(1+m \arg D_{i}\right)=P D_{i}$

CPI Function

$$
C P I_{t}=\frac{\sum_{i} P D_{i, t} * D_{i, t}^{F}}{\sum_{i} P D_{i, t 0} * D_{i, t 0}^{F}}
$$

$P D_{i, t}$ is demand price, $D_{i, t}^{F}$ is food demand, $P D_{i, t 0}$ is demand price of base year. 